\title{
Я.М. Кожушко
}

Харківський національний університет Повітряних Сил ім. I. Кожедуба, Харків

\section{ПРОТИДІЯ НАПІВАКТИВНИМ ЛАЗЕРНИМ СИСТЕМАМ НАВЕДЕННЯ НА ОСНОВІ ЗАСТОСУВАННЯ ДИФРАКЦІЙНО-ВІДБИВАЮЧИХ ПОКРИТТІВ}

Запропоновано підхід до врахування протидї напівактивним лазерним системам наведення під час застосування дифракиійно-відбиваючих покриттів за рахунок використання таких покриттів для досягнення поставленої мети. Підхід передбачає отримання імовірнісних інтервальних оцінок при заданих значеннях величини інтервалу, щьо визначають якість слідкуючих систем наведення, які дочільно прийняти в якості оцінок ефективності методів протидї напівактивним лазерним системам наведення за допомогою вдосконалення існуючого математичного апарату.

Ключові слова: дифракційно-відбиваюче покриття, лазер, радіоелектронний засіб, система наведення, слідкуюча система, фотоприймач.

\section{Вступ}

Постановка проблеми. В умовах сучасних бойових дій за великої кількості радіоелектронних об'єктів і радіоелектронних засобів (РЕЗ) наземного та повітряно-космічного базування [1-5], постійно розширюється номенклатура засобів поразки, активно випробовуються та застосовуються нові зразки озброєння, випробовуються та застосовуються системи та засоби протидії ним. При цьому, все більшу значимість становлять лазерні системи наведення, та системи на їх основі, які є сучасними, цифровими, точними, скритними, високотехнологічними, достатньо малогабаритними та у своєму спектрі достатньо перешкодо захищеними. Тому планування застосування РЕ3 [6-10] у більшості випадків потребує прогнозування відношення сигнал/шум на входах приймачів, які розлядаються, за розрахунками, що проводяться в умовах невизначеності та за їх невідомого положення. Ця потреба, а також обов'язковість врахування умов поширення електромагнітних хвиль, обумовлюють необхідність оцінювання відношення перешкода/сигнал для кожної точки значної просторової області, а отже великих обчислювальних витрат.

Аналіз останніх досліджень та публікацій. Оцінювання можливостей з протидії системам наведення різних типів є багатофакторне, налічує різні методи та методики [11-17]. Серед них своє місце займає напрямок лазерних систем самонаведення, що грунтується на відомих підходах. Застосування дифракційно-відбивних покриттів задля протидії лазерному випромінюванню [18-23] вимагає уточнення математичного апарату для оцінки вибору такого матеріалу.

Таким чином, мета статті полягає в обгрунтуванні математичного апарату для оцінки протидії напівактивним лазерним системам наведення при застосуванні дифракційно-відбиваючих покриттів.

\section{Виклад основного матеріалу}

Ефективність функціонування напівактивних лазерних систем наведення визначається схемою обробки імпульсних оптичних сигналів, відбитих від об'єкта, що підсвічується. Основним завданням системи наведення, схема обробки відбитих сигналів в якій представлена на рис. 1, є наведення боєприпасу на об'єкт, що атакується 3 мінімально можливими кутовими помилками.

Оцінку ефективності слідкуючих напівактивних лазерних засобів наведення доцільно проводити на основі функції щільності ймовірності сигналу помилки $f(\varepsilon)$ [24], так як дана функція дозволяє проводити розрахунок ймовірностей знаходження сигналів кутових помилок в певних інтервалах при заданих значеннях сигналів кутових помилок.

Оцінювання ефективності методів протидії напівактивним лазерним системам наведення, метою яких $є$ забезпечення максимально можливих значень кутових помилок наведення, доцільно проводити на основі інтервальних оцінок виду:

$$
P\left(\varepsilon \leq\left|\varepsilon_{c} \pm \frac{\Delta \varepsilon}{2}\right|\right)=\int_{\varepsilon_{c}-\frac{\Delta \varepsilon}{2}}^{\varepsilon_{c}+\frac{\Delta \varepsilon}{2}} f(\varepsilon) d \varepsilon
$$

де $P\left(\varepsilon \leq\left|\varepsilon_{c} \pm \frac{\Delta \varepsilon}{2}\right|\right)$ - ймовірність потрапляння сигналу помилки в інтервал $\Delta \varepsilon$ при поступаючому в систему обробки сигналу помилки $\varepsilon_{C}$.

Для пристрою обробки сигналів чотириквадрантного фотоприймача визначимо функцію щільності ймовірності сигналу помилок і проведемо ii аналіз 3 точки зору застосування інтервальних оцінок виду 


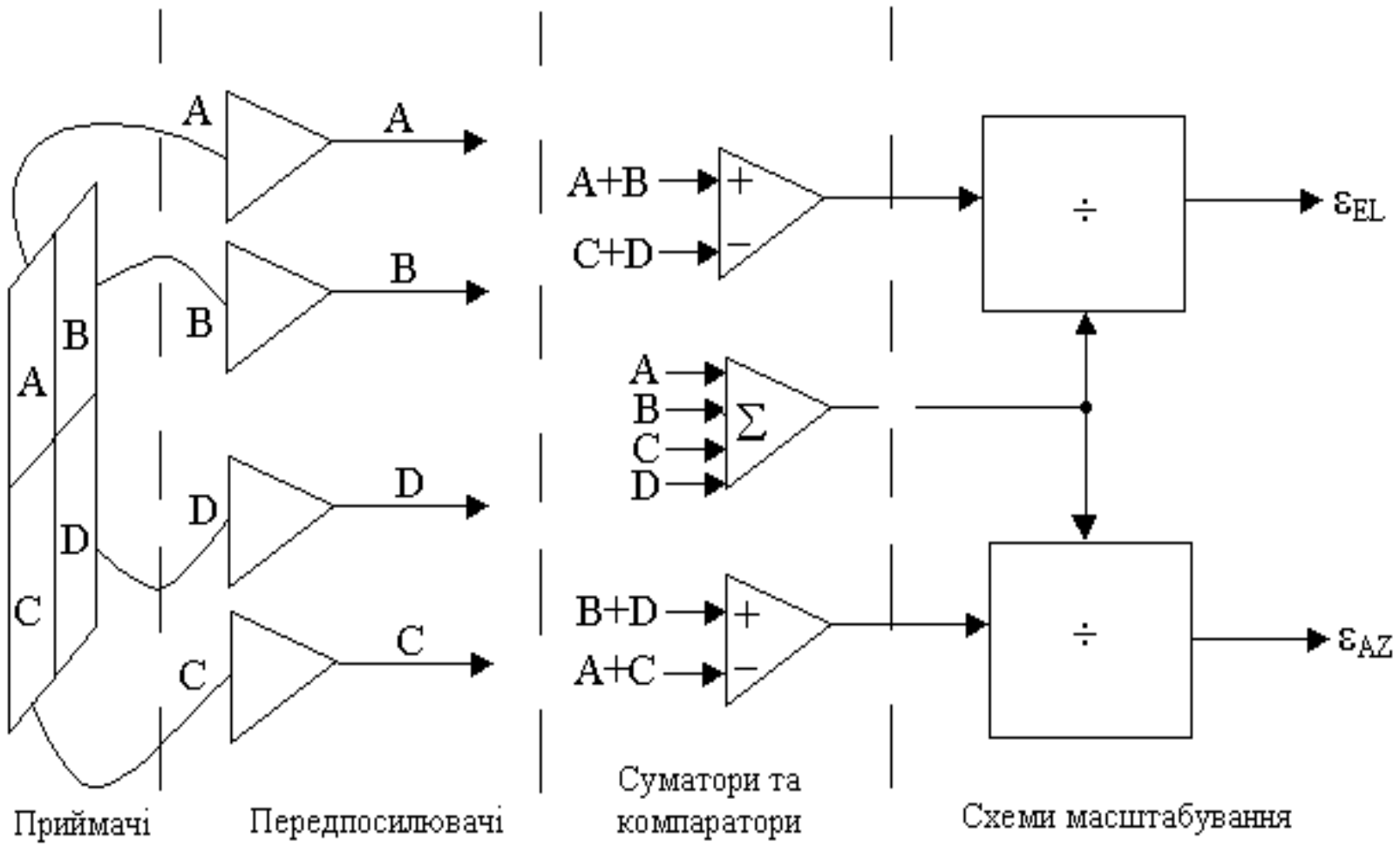

Рис. 1. Функціональна схема обробки сигналів в імпульсній лазерній слідкуючій системі Джерело: розроблено автором за даними [24].

(1) для оцінки ефективності застосування засобів протидії напівактивним лазерним системам наведення.

Відношення сигнал - шум на вході кожного попереднього підсилювача виражається через відношення струмів [24-27]:

$$
g=\frac{i_{S}}{i_{N}},
$$

де $i_{S}$ - струм корисного сигналу на виході квадрантного фотоприймача;

\section{$i_{N}$ - струм шуму.}

Струм корисного сигналу визначається співвідношенням [26-27]:

$$
i_{S}=S_{\lambda} P_{C}
$$

де $S_{\lambda}$ - спектральна чутливість фотоприймача;

$P_{C}$ - потужність оптичного сигналу, відбитого від об'єкта, що надходить на вхід фотоприймача.

Струм шуму фотоприймача визначається ефектом дробового шуму кожного квадранта фотоприймача, що викликається фоном і темновим струмом, $\mathrm{i}$ тепловим шумом. Струм дробового шуму виражається співвідношенням [24; 26]:

$$
i_{N 1}=\sqrt{2 e\left(S_{\lambda} P_{\Phi}^{v} \Delta v+i_{T}\right) \Delta f},
$$

де $e$ - заряд електрона;
$P_{\Phi}^{v}$ - спектральна щільність фонового випромінювання;

$\Delta v$ - ефективна смуга пропускання оптичного фільтра;

$$
\begin{aligned}
& i_{T} \text { - темновий струм; } \\
& \Delta f \text { - електрична смуга пропускання фото- }
\end{aligned}
$$
приймача.

Вираз (4) визначає струм дробового шуму, не враховуючи можливості постановки оптичних перешкод стороною, що захищається. Тому в загальному випадку струм дробового шуму у фотоприймачі слідкуючих систем наведення керованих боєприпасів слід оцінювати за співвідношенням:

$$
i_{N 1}=\sqrt{2 e\left(S_{\lambda} P_{\Phi}^{v} \Delta v+S_{\lambda} P_{\Pi}^{v} \Delta v+i_{T}\right) \Delta f},
$$

де $P_{\Pi}^{v}$ - спектральна щільність випромінювання постановника перешкод, що потрапляє в поле зору приймача слідкуючої системи наведення.

У разі постановки перешкод лазером на довжині хвилі лазера станції підсвітки, а також застосування стороною, що захищається, хибних відбиваючих цілей, вираз (4) перетворюється:

$$
i_{N 1}=\sqrt{2 e\left(S_{\lambda} P_{\Phi}^{v} \Delta v+S_{\lambda} P_{\Pi}+i_{T}\right) \Delta f},
$$

де $P_{\Pi}$ - потужність сигналу перешкоди. 
Залежно від умов застосування противником керованих боєприпасів оцінювати струм дробового шуму слід на основі співвідношень (4-6).

У свою чергу, струм теплового шуму резистивної частини навантаження визначається як [24-27]:

$$
i_{N 2}=\sqrt{\frac{4 k_{B} T \Delta f}{R_{L}}},
$$

де $k_{B}$ - стала Больцмана;

$T$ - абсолютна температура опору навантаження $R_{L}$.

На основі співвідношень (4) - (7) теоретично оцінимо величину шумового струму, що надходить на вхід попереднього підсилювача разом з струмом корисного сигналу, наступним чином:

$$
i_{N}=\sqrt{i_{N 1}^{2}+i_{N 2}^{2}} \text {. }
$$

Для оцінки характеристик сигналу помилки при наявності шуму і перешкод вважають, що шум $\mathrm{i}_{\mathrm{N} 3}$ від попереднього підсилювача має гаусів закон розподілу. Для того, щоб краще відобразити фактор шуму на виході кожного квадрантного попереднього підсилювача, вираз (8) представляється в наступному вигляді:

$$
i_{N}=\sqrt{i_{N 1}^{2}+i_{N 2}^{2}+i_{N 3}^{2}} .
$$

Вираз для щільності ймовірності сигналу помилки по одній осі можна отримати для випадку, коли в кожному квадранті фотоприймача $€$ джерело шуму $i_{N} 3$ дисперсією $\sigma_{N^{2}}$ i середнім значенням, рівним нулю [24].

Реальний сигнал помилки, що формується на борту джерела лазерного випромінювання по одній осі можна представити у вигляді:

$$
\varepsilon=\frac{S_{D}+N_{1}}{S_{S}+N_{2}}=\frac{U-V}{U+V},
$$

де $S_{D}$ - попарний різницевий сигнал для квадрантів на даній осі;

$S_{S}$ - сумарний сигнал для всіх квадрантів фотоприймача;

$N_{1}$ - середньоквадратичне значення шуму, пов'язаного з різницевим сигналом;

$\mathrm{N}_{2}$ - середньоквадратичне значення шуму, пов'язаного з сумарним сигналом.

$N_{1}$ та $N_{2}$ не є взаємно незалежними параметрами, тому що являють собою різні поєднання шумів одних і тих же квадрантів.

Випадкові змінні $U$ та $V$ з гаусовим законом розподілу представляють собою попарно сигнали 3 чутливих елементів приймача слідкуючої системи і пов'язані співвідношеннями:

$$
\begin{aligned}
& U=u+N_{U} . \\
& V=v+N_{V} .
\end{aligned}
$$

де:

$$
\begin{aligned}
& u-v=S_{D} . \\
& u+v=S_{S} .
\end{aligned}
$$

На основі врахування співвідношень (10-14) в [24] отримано наступний вираз для щільності ймовірності сигналу помилки:

$$
\begin{gathered}
f(\varepsilon)=\frac{1}{\pi\left(1+\varepsilon^{2}\right)} e^{\left(-1 / 2 \sigma_{p}^{2}\right)\left(u^{2}+v^{2}\right)} \times \\
\times\left[1+\sqrt{2 \pi} B e^{B^{2} / 2} \int_{0}^{B} \frac{1}{\sqrt{2 \pi}} e^{-\alpha^{2} / 2} d \alpha\right],
\end{gathered}
$$

де $B=\frac{1}{\sqrt{2 \sigma_{p}^{2}}} \frac{(1+\varepsilon) u+(1-\varepsilon) v}{\sqrt{1+\varepsilon^{2}}}$;

$\sigma_{p}^{2}=2 \sigma_{n}^{2}-$ дисперсія як змінної $U(11)$, так й змінної $V$ (12).

За виразом (15) для заданого значення сигнал шум $\left(S_{S} / 2 \sigma_{p}^{2}\right)$ можливо побудувати графіки щільності ймовірності сигналу помилки в залежності від очікуваної величини помилки, яка визначається відношенням $S_{D} / S_{S}$, де $0 \leq S_{D} / S_{S} \leq 1$.

На рис. 2. та рис. 3 наведені розраховані в математичному програмному пакеті Mathcad 2000 графіки функції щільності ймовірності сигналу помилки для значень відношення сигнал-шум $S_{S} / 2 \sigma_{p}^{2}=5 ; \quad S_{S} / 2 \sigma_{p}^{2}=10 ; \quad S_{S} / 2 \sigma_{p}^{2}=20$; $S_{S} / 2 \sigma_{p}^{2}=40$ при очікуваних величинах помилки $\varepsilon_{C}=0$ і $\varepsilon_{c}=0,2$ відповідно.

Аналіз представлених залежностей показує, що функція щільності ймовірності розширюється при зменшенні відносини сигнал-шум, отже, сигнали помилки містять тим більше шуму, ніж менш значення відносини сигнал-шум.

Так, $\quad$ для $\quad S_{S} / 2 \sigma_{p}^{2}=5 ; \quad S_{S} / 2 \sigma_{p}^{2}=10$; $S_{S} / 2 \sigma_{p}^{2}=20 ; \quad S_{S} / 2 \sigma_{p}^{2}=40$ ймовірність знаходження сигналу кутової помилки в інтервалі довжиною $\Delta \varepsilon=0,2$ та центром, що відповідає очікуваному значенню помилки $\varepsilon_{c}=0$, складає $P\left(\varepsilon \leq\left|\varepsilon_{C} \pm \frac{\Delta \varepsilon}{2}\right|\right)=0,518 ; \quad P\left(\varepsilon \leq\left|\varepsilon_{C} \pm \frac{\Delta \varepsilon}{2}\right|\right)=0,680 ;$ 0,841; 0,953 відповідно.

Аналогічні інтервальні оцінки, зроблені для $\varepsilon_{C}=0,2, \quad$ відповідають $\quad P\left(\varepsilon \leq\left|\varepsilon_{c} \pm \frac{\Delta \varepsilon}{2}\right|\right)=0,510$; 0,671; 0,833; 0,949.

Вочевидь, що відповідні інтервальні оцінки істотно визначаються величиною інтервалу $\Delta \varepsilon$. 
Отримані значення ймовірностей складають $P\left(\varepsilon \leq\left|\varepsilon_{C} \pm \frac{\Delta \varepsilon}{2}\right|\right)=0,056 ; \quad P\left(\varepsilon \leq\left|\varepsilon_{C} \pm \frac{\Delta \varepsilon}{2}\right|\right)=0,080$; $P\left(\varepsilon \leq\left|\varepsilon_{C} \pm \frac{\Delta \varepsilon}{2}\right|\right)=0,112 ; \quad P\left(\varepsilon \leq\left|\varepsilon_{c} \pm \frac{\Delta \varepsilon}{2}\right|\right)=0,159$ для $\quad \varepsilon_{c}=0 \quad$ та $\quad P\left(\varepsilon \leq\left|\varepsilon_{c} \pm \frac{\Delta \varepsilon}{2}\right|\right)=0,055$; $P\left(\varepsilon \leq\left|\varepsilon_{C} \pm \frac{\Delta \varepsilon}{2}\right|\right)=0,078 ; 0,11 ;=0,155$ для $\varepsilon_{C}=0,2$.
Таким чином, імовірнісні інтервальні оцінки виду (1) при заданих значеннях величини інтервалу, що визначають якість слідкуючих систем наведення, доцільно прийняти в якості оцінок ефективності методів протидії напівактивним лазерним системам наведення.

Такі оцінки дозволять кількісно визначити ступінь зниження ефективності процесу наведення джерела випромінювання на ціль при зменшенні відносини сигнал-шум на вході оптичної системи джерела випромінювання.

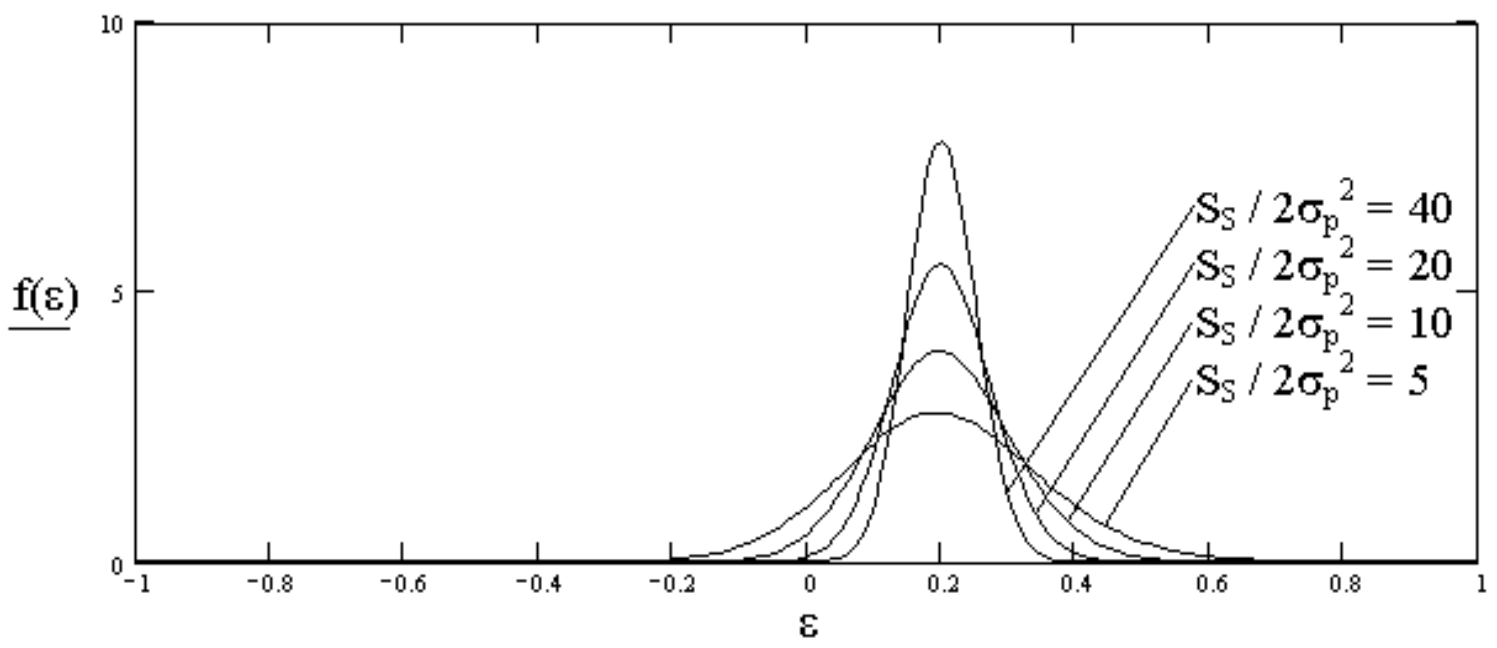

Рис. 2. Графіки щільності ймовірності для нормалізованого сигналу помилки $S_{\mathrm{D}} / S_{\mathrm{S}}=0,2$

Джерело: розроблено автором за даними [24].

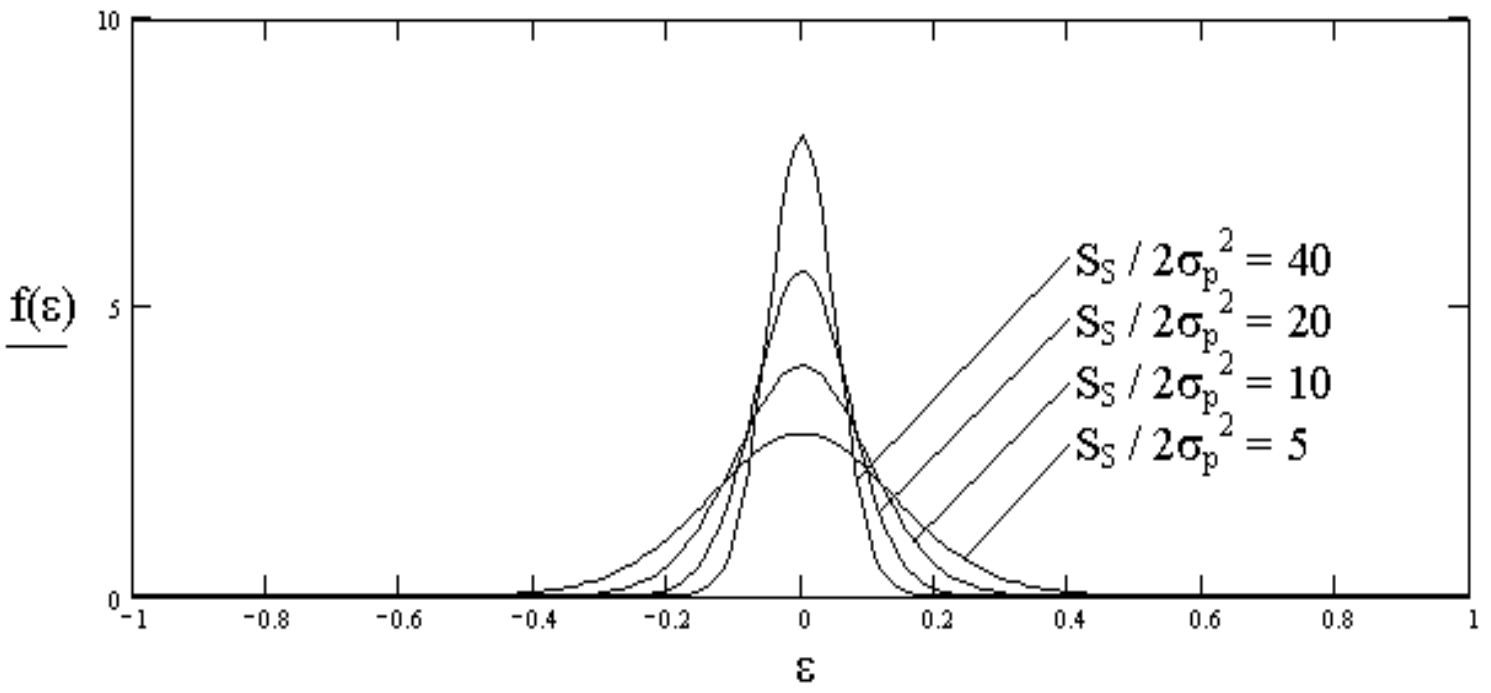

Рис. 3. Графіки щільності ймовірності для нормалізованого сигналу помилки $S_{\mathrm{D}} / S_{\mathrm{S}}=0$

Джерело: розроблено автором за даними [24]. 


\section{Висновки}

Одним $з$ ефективних рішень завдання протидії напівактивним лазерним системам наведення $\epsilon$ розробка засобів, що дозволяють зменшити інтенсивність відбитого від об'єкта випромінювання в напрямку джерела лазерного випромінювання і формувати в поле зору системи наведення оптичні перешкоди.

Технічні рішення, що передбачають застосування дифракційно-відбивних покриттів, є перспективними для протидії напівактивним лазерним системам наведення.

Принцип застосування дифракційно відбивних покриттів полягає в перерозподілі енергії розсіяного випромінювання в просторі, тобто в переході від рівномірного розсіювання, що описується законом Ламберта, до істотно нерівномірного розподілу інтенсивності випромінювання, характерному для відбиття світла на дифракційних решітках.

Використання дифракційно-відбиваючих покриттів дозволяє досягти істотного зменшення потужності оптичного сигналу, відбитого від поверхні 3 покриттям, в широкому діапазоні кутів відбиття та значного збільшення потужності відбитого сигналу у вкрай вузькому секторі кутів відбиття.

При відповідних параметрах і орієнтації дифракційно-відбиваючого покриття можливе суміщення напрямку головного дифракційного максимуму діаграми вторинного розсіювання 3 напрямком на земну (підстилаючу) поверхню, що забезпечить формування на ній перевідбитої світлової плями, що є оптичною перешкодою.

Таким чином, виявляється перспективність застосування таких покриттів для протидії напівактивним лазерним системам наведення, яка визначається тим фактом, що дифракційно-відбивне покриття може одночасно використовуватися як маловідбиваюче покриття для протидії лазерним системам наведення (метод зменшення інформації про об'єкт, що захищається), що забезпечує зменшення величини струму корисного сигналу, а також як засіб постановки оптичних перешкод на підстильної поверхні (метод зсуву точки наведення), що передбачає збільшення струму шуму в приймачі системи наведення.

Наведено обгрунтування математичного апарату для оцінки протидії напівактивним лазерним систем наведення при застосуванні дифракційновідбиваючих покриттів.

Проведені практичні розрахунки для отримання орієнтовних значень, що характеризують щільність ймовірності для нормалізованого сигналу помилки, 3 метою оцінки можливості застосування запропонованого математичного апарату, показали несуперечність та теоретичну можливість його фізичної реалізації та подальшого застосування на практиці.

\section{Список літератури}

1. Алімпієв А.М. Особливості гібридної війни РФ проти України. Досвід, що отриманий Повітряними Силами Збройних Сил України / А.М. Алімпієв, Г.В. Пєвцов // Наука і техніка Повітряних Сил Збройних Сил України. - 2017. № 2(27). - C. 19-25.

2. McDermott R.N. Russia's electronic warfare capabilities to 2025 [Електронний pecypc] / R.N. McDermott // International center for defense and security. - $2017 . \quad$ - 48 р. - Режим доступу: https://icds.ee/wpcontent/uploads/2018/ICDS_Report_Russias_Electronic_Warfare_to_2025.pdf.

3. Ruifang Ye. The future development of foreign military electronic warfare UAVs / Ye. Ruifang, Wu. Tanran, Ren. Xiangyu // Aerospace Electronic Warfare. - 2013. - Vol. 2. - P. 12-15.

4. Тенденции развития авиационных средств радиоэлектронной борьбы военно-воздушных сил Соединенных Штатов Америки / Я.М. Кожушко, А.И. Резниченко, Ю.А. Олейник, А.А. Михайлик // Наука і техніка Повітряних Сил Збройних Сил України. - 2011. - № 2(6). - С. 44-48.

5. Радзиевский В.Г. Современная радиоэлектронная борьба. Вопросы методологии / В.Г. Радзиевский, А.А. Агафонов. - М.: Радиотехника, 2006. - 424 с.

6. NATO Standard AJP-3.3. Allied Joint Doctrine for air and space operations. Edition B, Version 1. NSO, April 2016. - 100 p.

7. Радіоелектронне подавлення комплексів бістатичної локації “на просвічування" / В.Й. Климченко, В.О. Тютюнник, І.М. Трофимов, Д.А. Дончак // Системи озброєння і військова техніка. - 2019. - № 3(59). - С. $72-78$. https://doi.org/10.30748/soivt.2019.59.09.

8. Кирилюк В.А. Критерій вибору позиції станції перешкод бортовим радіолокаційним станціям / В.А. Кирилюк // Збірник наукових праць “Труди університету”. - 2011. - № 1(103). - С. 155-160.

9. Методика використання малопотужних наземних передавачів активних шумових перешкод для імітації перешкодової обстановки оглядовим радіолокаційним станціям / В.Й. Климченко, С.В. Кукобко, В.О. Тютюнник, Г.В. Рибалка // Системи озброєння і військова техніка. - 2018. - № 4(56). - С. 27-34 https://doi.org/10.30748/soivt.2018.56.04.

10. Підвищення ролі радіоелектронної боротьби за досвідом локальних війн / Я.М. Кожушко, Г.В. Мегельбей, А.І. Резниченко, Ю.А. Олійник // Збірник наукових праць Харківського національного університету Повітряних Сил. 2012. - № 3(32). - C. 79-81.

11. Basing of the television-picture generator application for distance monitoring of turbulent atmosphere // G.N. Dolya, A.N. Katunin, A.N. Bulay, E.S. Chudovskaja // Conference Proceedings - 5th International Conference on Advanced Optoelectronics and Lasers, CAOL' 2010. - 2010. - C. 193-195. 
12. Statistical analysis of harmonic signals for testing of electronic devices / S. Herasimov, E. Roshchupkin, V.Kutsenko, S. Riazantsev, Y. Nastishin // International Journal of Emerging Trends in Engineering Research. - 2020. - Vol. 8(7) P. 3791-3798. https://doi.org/10.30534/ijeter/2020/143872020.

13. Коломійцев О.В. Лазерна інформаційно-вимірювальна система 3 можливістю пошуку літального апарата /

О.В. Коломійцев // Системи озброєння і військова техніка. - 2009. - № 3(19). - С. 22-24.

14. Доля Г.Н. Сравнительный анализ возможностей методов интерферометрии для наблюдения фазовых неоднородностей в воздушной среде / Г.Н. Доля, А.Н. Катунин, В.М. Мазанов // Восточно-Европейский журнал передовых технологий. - 2006. - № 2(20). - С. 61-64.

15. Testing Signals for Electronics: Criteria for Synthesis / S. Herasimov, V. Pavlii, O. Tymoshchuk, M. Yakovlev, D. Khaustov, Y. Ryzhov, L. Sakovych, Y. Nastishin // Journal of Electronic Testing: Theory and Applications (JETTA). - 2019. - Vol. 35(3). - P. 349-357. https://doi.org/10.1007/s10836-019-05798-9.

16. Laser radiation parameters at detection of decay and fire sources / G.N. Dolya, A.N. Katunin, K.V. Sadovy, E.S. Chudovskaja // Proceedings of CAOL 2008: 4th International Conference on Advanced Optoelectronics and Lasers. - 2008. - P. 351-353.

17. Быков В.Н. Обобщенная модель процесса функционирования матричной радиометрической корреляционноэкстремальной системы навигации миллиметрового диапазона / В.Н. Быков, А.М. Сотников, Я.Н. Кожушко // Системи управління, навігації та зв’язку. - 2009. - № 3(11). - С. 13-17.

18. Катунин А.Н. Применение дифракционно отражающих покрытий для защиты наземных целей от высокоточного оружия с полуактивным лазерным наведением / А.Н. Катунин // Системи обробки інформації. - 2002. - № 6(22). C. 266-272.

19. Evaluation of surface profile of holographic diffraction reflective coatings on scattering chart using in laser alarm systems / S. Herasimov, Y. Kozhushko, E. Roshchupkin, V. Dekadin, V. Djus, Y. Melenti // International Journal of Emerging Trends in Engineering Research. - 2020. - Vol. 8(8). - P. 4502-4507. https://doi.org/10.30534/ijeter/2020/74882020.

20. Information analysis of multi-frequency signals of laser information measuring system / S. Herasimov, O. Tymochko, O. Kolomiitsev, G. Aloshin, O. Kriukov, O. Morozov, V. Aleksiyev // Physics and Engineering (EUREKA). - 2019. - Vol. 5. P. 19-28. https://doi.org/10.21303/2461-4262.2019.00984.

21. Dolya G.N. Opportunity of reduction of objects visibility using diffraction-reflecting coverings in conditions of application laser detection systems / G.N. Dolya, A.N. Katunin, G.A. Moiseyeva // Proceedings of LFNM 2001 - 3rd International Workshop on Laser and Fiber-Optical Networks Modeling. - 2001. - P. 136-139.

22. Доля Г.М. О возможности снижения заметности целей при защите от высокоточного оружия (ВТО) на основе использования дифракционно отражающих покрытий / Г.М. Доля, А.Н. Катунин // Збірник наукових праць Харківського військового університету. - 2000. - № 2(28). - С. 75-81.

23. Usage of Lidar Systems for Detection of Hazardous Substances in Various Weather Conditions // O. Kulakov, A. Katunin, Ya. Kozhushko, S. Herasymov, O. Roianov, T. Gorbach // IEEE 6th International Symposium on Microwaves, Radar and Remote Sensing (MRRS). - 2020. - P. 360-363.

24. Вольф У. Справочник по инфракрасной технике / У. Вольф; под ред. Г. Цисис. - М.: Мир, 1999. - 472 с.

25. Лазарев Л.П. Оптико-электронные приборы наведения / Л.П. Лазарев. - М.: Машиностроение, 1989. - 510 с.

26. Москвитин С.В. Теоретические основы оптической локации / С.В. Москвитин, А.И. Стрелков. - Х.: ХВУ, 1992. -368 c.

27. Малашин М.С. Основы проектирования лазерных локационных систем / М.С. Малашин, Р.П. Каминский, Ю.Б. Борисов. - М.: Высшая школа, 1983. - 207 с.

\section{Відомості про автора:}

\section{Кожушко Ярослав Миколайович}

кандидат технічних наук старший науковий співробітник

Харківського національного університету

Повітряних Сил ім. І. Кожедуба

Харків, Україна

https://orcid.org/0000-0002-4229-6757

\section{Information about the author:}

\section{Yaroslav Kozhushko}

Candidate of Technical Sciences

Senior Research Associate

of Ivan Kozhedub Kharkiv National

Air Force University,

Kharkiv, Ukraine

https://orcid.org/0000-0002-4229-6757 
ПРОТИВОДЕЙСТВИЕ ПОЛУАКТИВНЫМ ЛАЗЕРНЫМ СИСТЕМАМ НАВЕДЕНИЯ НА ОСНОВЕ ПРИМЕНЕНИЯ ДИФРАКЦИОННО ОТРАЖАЮЩИХ ПОКРЫТИЙ

\author{
Я.Н. Кожушко
}

Предложено подход к учету противодействию полуактивным лазерным системам наведения при применении дифракционно-отражающих покрытий за счет применения таких покрытий для достижения поставленной иели. Подход предусматривает получение вероятностных интервальных оценок при заданных значениях величинь интервала, что определяют качество следящуи систем наведения, которые целесообразно принять в качестве оценок эффективности методов противодействия полуактивным лазерным системам наведения при помощи усовершенствования существующего математического аппарата.

Ключевые слова: дифракиионно-отражающее покрытие, лазер, радиоэлектронное средство, система наведения, следящая система, фотоприемник.

\title{
COUNTERACTING SEMI-ACTIVE LASER GUIDANCE SYSTEMS BASED ON APPLICATION OF DIFFRACTIVE REFLECTIVE COATINGS
}

\section{Ya. Kozhushko}

An approach to taking into account the resistance of semi-active laser guidance systems during the application of diffraction-reflecting coatings through the use of such coatings to achieve this goal is proposed. The approach involves obtaining probabilistic interval estimates at given values of the interval, which determine the quality of tracking guidance systems, which should be taken as evaluations of the effectiveness of methods of counteracting semi-active laser guidance systems by improving the existing mathematical apparatus. The prospects for the use of such coatings to counteract semi-active laser guidance systems, which is determined by the fact that the diffraction-reflective coating can be used as a low-reflecting coating to counteract laser guidance systems (method of reducing information about the protected object), which reduces the magnitude of the current of the useful signal, as well as a means of setting optical interference on the underlying surface (method of shifting the point of guidance), which involves increasing the noise current in the receiver of the guidance system. Probabilistic interval estimates at given values of the value of the interval, which determine the quality of the tracking guidance systems, it is advisable to take as estimates of the effectiveness of methods of counteraction to semi-active laser guidance systems. Such estimates will allow to quantify the degree of reduction of the efficiency of the process of directing the radiation source to the target while reducing the signalto-noise ratio at the input of the optical system of the radiation source. In the article the substantiation of the mathematical device for estimation of resistance to semi-active laser guidance systems at application of diffraction-reflecting coverings is resulted. The practical calculations to obtain approximate values, in order to assess the feasibility of the proposed mathematical apparatus, showed the consistency and theoretical feasibility of its application.

Keywords: diffractive-reflecting coating, laser, electronic means, guidance system, tracking system, photodetector. 